\title{
MARTÍN ADÁN: DE LA URBE MODERNA A LA CIUDAD ANCESTRAL
}

\author{
Eva $M^{a}$ Valero Juan \\ Universidad de Alicante
}

\begin{abstract}
This paper proposes a reflection about the social transformation of Lima in the $20 \mathrm{~s}$ and $30 \mathrm{~s}$, described by Martín Adán in La casa de cartón (1928) through surrealists and modernist images, opposed to the "city of stone", Machu Pichu, that the poet describes in La mano desasida (19611964). A duality that, through these two main works of the author's prose and poetry, permits to research in the literary evolution of one of the main figures of the 20th century Peruvian literature.
\end{abstract}

El tratamiento literario de la temática urbana ha permitido analizar modelos de ciudades literarias que irradian nuevos enfoques para abordar la obra de determinados autores. En la literatura peruana son múltiples los ejemplos que componen la trayectoria de una prolífica literatura urbana que recorre las constantes mutaciones de la Lima contemporánea y la problemática social y cultural que de ellas se deriva. Si nos remontamos a su fundación en 1535 , la tradición urbana se convierte en el caleidoscopio que nos ofrece las diversas caras que Lima fue adquiriendo al compás de la historia: así, la Ciudad de los Reyes fue el jardín perfumado de los cronistas, la ciudad frívola de satíricos como Juan del Valle y Caviedes, la ciudad costumbrista de Manuel Ascencio Segura y Felipe Pardo y Aliaga, la ciudad mítica creada por Ricardo Palma en sus Tradiciones peruanas, la "ciudad de la gracia" que vieron Rubén Darío y los escritores peruanos de entresiglos y, finalmente, la Lima horrible del nuevo siglo, de Sebastián Salazar Bondy y la generación del 50, pero también de algunos predecesores fundamentales. Entre estos se encuentra Martín Adán como figura principal de esta tradición literaria urbana; un poeta "insular" en la literatura peruana contemporánea que, a finales de los años veinte, trazó las primeras imágenes de la transformación de su ciudad natal.

Pero la perspectiva urbana que pretendo abordar en estas páginas no se circunscribe tan sólo al espacio limeño, teniendo en cuenta que la poesía de Adán transita no sólo por Lima sino por otro espacio urbano especialmente significativo en la evolución de su poética. Martín Adán -descendiente de la antigua aristocracia en declive- fue testigo privilegiado de la transformación de su ciudad, que tomó como primer referente literario, y su obra nos conduce desde la problemática de la Lima de las primeras décadas del siglo (en sus primeros escritos) hacia la ciudad ancestral de los Incas, Machu Picchu, que protagoniza el extenso poema titulado La mano desasida. El enfoque urbano nos abre así un nuevo camino para la exploración de esta obra cuya evolución, como veremos, está estrechamente ligada con ambas imágenes contrapuestas: Lima y Machu Picchu.

Pero comencemos remontándonos a los orígenes. Y para ello creo necesario recurrir a una irónica frase de Martín Adán especialmente significativa en cuanto a la motivación 
temática de su primera escritura: "Lima tiene muy hermosos crepúsculos. Yo, por ejemplo...". Como ha visto Sebastián Salazar Bondy a propósito de estas palabras, "es lícito pensar que ese ocaso no es el de su persona en tensión, ni el de su obra de permanente calidad, sino el de una clase, a la que representa y la cual no lo reconoce" ${ }^{\text {. }}$. Siguiendo esta acertada interpretación, en la declaración de Adán podemos encontrar una clave fundamental de su primera producción: el estupor ante la constante mutación de la ciudad y de su sociedad como motivo que alienta la escritura del cambio urbano. En dicha frase, además, se encuentra prefigurado el perfil del poeta que emerge de la crisis de la alta burguesía peruana desde comienzos de siglo: el hombre desarraigado, solo, y finalmente marginal en un mundo que lo convierte en el loco, en el iluminado, en el místico; o, recurriendo nuevamente a Salazar Bondy, en el "parroquiano de tabernas"2 "descuidado", "huidizo y sardónico"3 que vivió el terrible "crepúsculo" de la famosa "Lima que se va", cuyo origen literario hay que buscarlo en las Tradiciones de Ricardo Palma.

Había nacido en Lima en 1908, y ya en los años veinte sorprendió con su precoz vocación literaria en el panorama de aquella literatura peruana que veneraba a los renovadores de comienzos de siglo -Abraham Valdelomar y José María Eguren como maestros indiscutibles- y clausuraba, en el contexto de la reforma universitaria de 1919, las propuestas literarias de la generación del $900^{4}$. Una insólita literatura urbana asomaba en la Lima del nuevo siglo, aunque en sus primeras décadas todavía no cesaban los empeños de algunos novecentistas por rescatar y evocar imágenes y costumbres de la desaparecida Ciudad de los Reyes, ni se agotaban las lágrimas derramadas con insistencia en aquella literatura evocadora y quejumbrosa ante la marcha imperiosa de "la Lima que se va", alimentada por José Gálvez, Enrique A. Carrillo "Cabotín" o Luis Alayza, entre otros. Ahora bien, en algunas de sus obras, estos escritores no sólo daban su adiós al hortus clausum virreinal, imagen de la ciudad colonial cerrada por las murallas que se construyeron en 1685; también saludaban la llegada de los nuevos tiempos con su carga de problemas derivados del cambio social ante la incipiente migración de las provincias, que comenzaba a producirse en las primeras décadas del veinte.

El inédito paisaje urbano demandaba urgentemente una nueva literatura que penetrara en su vertiginosa mutación física y social. En este espacio, el joven Rafael de la Fuente Benavides (posteriormente de pseudónimo Martín Adán) comienza su andadura literaria. Asiste a las tertulias domingueras en la casa barranquina de Eguren $^{5}$-a la que acudían,

\footnotetext{
${ }^{1}$ S. Salazar Bondy, "El conflicto vital de Martín Adán", en Martín Adán, Obra poética (1928-1971) (con una selección de juicios críticos), Lima, Instituto Nacional de Cultura, 1971 (pp. 257-262), p. 260.

${ }^{2}$ S. Salazar Bondy, "Noticias de Martín Adán y La mano desasida", Revista de la Universidad de México, n 1 , vol. XVI (septiembre 1961), México, p. 19.

3 "En cualquier café o bar de Lima es posible encontrar, perdido entre la múltiple fauna urbana, a un hombre descuidado en su traza y su traje (...) Sumido en sí, huidizo y sardónico, encasquetado un sombrero deforme, cubierto por un sobretodo basto, con la barba crecida...". S. Salazar Bondy, "El conflicto vital de Martín Adán", cit., pág. 262.

${ }^{4}$ El grupo de escritores congregado en 1916 en torno a la revista Colónida representó una insurrección "contra el academicismo y sus oligarquías, su énfasis retórico, su gusto conservador, su galantería dieciochesca y su melancolía mediocre y ojerosa". J. C. Mariátegui, Siete ensayos de interpretación de la realidad peruana, México, Era, 1979, p. 253.

${ }^{5}$ L. A. Sánchez, en el Prólogo a La casa de cartón, ratifica que "Eguren, en efecto, a quien dedica el libro, fue el númen tutelar de la infancia de Martín. Él le enseñó el amor a la palabra arisca y pudorosa; el desafecto por el
} 
entre otros, Enrique Bustamante y Ballivián, Manuel Beingolea, Percy Gibson, el cubano Mariano Brull, el español Juan Larrea ${ }^{6}$, y también a las que organizaba José Carlos Mariátegui en la calle Washington de Lima. En este escenario de la vanguardia urbana, Adán se distingue muy pronto como una de las figuras señeras de la renovación literaria ${ }^{7}$, sobre todo desde la publicación en 1927, en la revista Amauta, del primer anticipo de "La casa de cartón" 8 . Un año después, en 1928, aparecía la primera edición de esta obra (con prólogo de Luis Alberto Sánchez y colofón de José Carlos Mariátegui), donde De la Fuente Benavides, con apenas veinte años, se convierte ya en Martín Adán. El escritor inauguraba su proyecto literario con la invención de este nombre, que no es tanto un pseudónimo como la doble máscara con la que impregnó de ironía su nacimiento literario: concilia a Darwin (martín significa mono en Lima) con el primer hombre del Génesis, marcando el origen herético de su búsqueda incansable del yo entre máscaras que se contraponen ${ }^{9}$.

Definida por unos como novela poética y por otros como poema narrativo, La casa de cartón traza, a través de una intensa carga poética hecha de imágenes sorprendentes, el primer retrato de una Lima real y marginal; y potencia, a través de un vanguardismo ya tardío y muy subjetivo, el significado problemático de esa ciudad desnaturalizada, creando un fuerte contraste de imágenes entre un centro urbano sucio y horrible y el paisaje idílico del balneario de Barranco, donde todavía, en los años veinte, se sentían los ecos de la antigua ciudad colonial. Con ello, Adán daba continuidad a lo que podía considerarse ya una tradición concreta que había convertido este balneario en un topos literario desde comienzos de siglo, a través de las evocaciones de escritores como Eguren, en algunos de sus poemas, Manuel Beingolea, en su breve novela titulada Bajo las lilas, o José Díez Canseco, en Suzy, Las Urrutia y El mirador de los ángeles.

Frente a la ciudad tumultuosa, la tonalidad costumbrista de La casa de cartón fija el retrato del balneario tranquilo, silencioso y apacible; lugar acechado por la avalancha de lo gris pero donde todavía subsistían los colores y sus matices, las calzadas de piedra, las campanas y las carretas:

vocablo duro y plebeyo; el fervor de imaginero renacentista para su prosa; una patente de artista paciente, tenaz, delicadísimo. Pero Martín se emancipó de Eguren, porque no es fácil que nadie pueda permanecer en ese mundo único de José María". L. A. Sánchez, "Prólogo" a La casa de cartón, Lima, Mejía Baca, 1974, p. 10.

${ }^{6}$ J. A. Mora, "Introducción" a Martín Adán, El más hermoso crepúsculo del mundo (antología), México, F.C.E., 1992, p. 33

${ }^{7}$ Sobre la significación de Martín Adán en este contexto, su profesor Luis Alberto Sánchez lo considera la figura principal del grupo de escritores limeños que a mediados de los años 20 irrumpe bajo el influjo del surrealismo y produce una literatura ironizante y agnóstica: "Bajo apariencia de fe -escribe Sánchez- encerraban un agnosticismo recalcitrante. [...] Martín Adán, en La casa de cartón (1928) inaugura la renovación estética, que acentúa en sus Antisonetos. La casa de cartón sonríe surrealistamente de la vida provinciana, de la limeña, del balneario, de las viejas criollas, de los tranvías con su contradictoria carga de rutina y fuga. Allegada a la Nueva Revista Peruana, la promoción, de que es Martín gonfarolero, acentúa su perfil agnóstico y oteador de unas emociones más íntimas en Enrique Peña [...], en Emilio von Westphalen [...] en Xavier Abril...”. L. A. Sánchez, Panorama de la literatura del Perú, Lima, Milla Batres, 1974, pp. 146-147.

${ }^{8}$ Amauta, $\mathrm{n}^{\circ} 10$ (diciembre de 1927), Lima.

${ }^{9}$ A este respecto, José Carlos Mariátegui escribió en una nota a la primera edición de un fragmento de La casa de cartón en Amauta: "Su nombre, según él, reconcilia el Génesis con la teoría darwiniana. Le hemos objetado privadamente, que Martín llaman los monos [sic] sólo en Lima y el Barranco y que Adán es patronímico inverosímil. Mas si Martín Adán se llama así realmente, no cabe duda que se trata de un humorista y hereje de nacimiento". Ibidem, p. 16. 
Resplandece el yeso de las calles -el blanco, el amarillo, el verde claro, el azul celeste, el gris perlino- los colores perfectos, prudentísimos, de las casas de Barranco. [...] La campana de la una del día deshace en el aire fofo su borra de sonido, y cae sobre Barranco en vuelo de parvas, leves blancuras plumón de la hora que voló al mar. Fin de almuerzo que es soledad de calles, y argentino, cálido silencio, y rebrillar de calzadas de redondas piedras auríferas, de piedras de lecho de río, sedientas y acezantes. Una carreta se lleva en su chirriar y en su golpear toda la fiebre de un jirón de calles que se han recorrido -pesadillas, seres, platanales, amarguras, sístoles y diástoles sordos... - [...] Y un tranvía canta con toda el alma con la guitarra del camino de Miraflores, parda, jaranera, tristona, con dos cuerdas de acero, y en el cuello de ella, la cinta verde de una alameda que bate el aire del mar. Tranvía, zambo tenorio... ${ }^{10}$

Los recursos vanguardistas eran el instrumento idóneo para crear esa dicotomía de paisajes: junto a la pintura del sosiego barranquino, una profusión de metáforas surrealistas dibujan la imagen repulsiva o artificiosa de la ciudad moderna, construyendo una superposición de cuadros que fortalecen, por su contraste, la visión del cambio urbano. Adán revela la técnica utilizada en las primeras páginas de La casa de cartón, y lo hace, precisamente, tomando la ciudad como imagen central de su metáfora: "Y la ciudad es una oleografía que contemplamos sumergida en agua: las ondas se llevan las cosas y alteran la disposición de los planos" (p. 13). Partiendo de esta pintura difuminada y fragmentada, el escritor intensifica la realidad de la transformación urbana a través de una narrativa que sin embargo se aleja del realismo, y en la constante alteración de los planos, las "cosas" que se van adquieren el eco del recuerdo y persisten en el fondo del cuadro. A la evocación del balneario se enfrentan las imágenes vanguardistas de la Lima moderna:

Nos fuimos a Lima. En el asfalto pegajoso, chisporroteaban llantas de automóviles; al fin de cada jirón, un tramonto de raso dorado; los postes de teléfono se contraluminaban perfectamente... (p. 19)

-Los arrabales de Lima. Una fábrica de aceites hincha su barriga pringosa y sopla como una vieja borracha- Lima. (p. 25)

Lima, la sucia Lima, caballista, comercial, deportiva, nacionalista, tan seria [...] ¿Árboles...? -los faroles- troncos de arbustos que la luz tuerce y la sombra hace verdes. A las seis de la mañana, a las seis de la tarde, son los faroles lo más vegetal del mundo, de una manera analítica, sintética, científica, pasiva, determinante, botánica, simplísima -los troncos sostienen al extremo superior campanas de cristal que encierran flores amarillas. (pp. 50-51)

En estas visiones se adivina ya la Lima horrible de César Moro y Sebastián Salazar Bondy ${ }^{11}$. La fisonomía de esta nueva Lima era todavía, en 1928, una imagen inusitada en la literatura peruana. Fue Martín Adán quien reveló, por caminos distintos al realismo, otras realidades limeñas, entre ellas, el suburbio o la barriada, constituyendo de este modo una apertura temática substancial en el proceso de emergencia de la narrativa urbana en el

\footnotetext{
${ }^{10}$ M. Adán, La casa de cartón, Lima, Mejía Baca, 1974, pp. 37-38. Todos los fragmentos citados de esta obra pertenecen a esta edición.

${ }^{11}$ Lima, la horrible es el título del emblemático ensayo de Sebastián Salazar Bondy (Lima, Peisa, 1974), quien da comienzo a su obra con los últimos versos del poema de César Moro "Viaje hacia la noche", recogido en $L a$ tortuga ecuestre. Moro apunta al final del poema lugar y fecha, donde encontramos por primera vez el título utilizado por Salazar Bondy: Lima la horrible, 24 de julio o agosto de 1949, firmado César Moro [La tortuga ecuestre].
} 
Perú $^{12}$. En este sentido, Adán fue un pionero y un precedente fundamental del neorrealismo urbano desarrollado por la denominada Generación del 50, fundamentalmente por Enrique Congrains Martín, Oswaldo Reynoso, Carlos Eduardo Zavaleta, Luis Loayza, Sebastián Salazar Bondy y Julio Ramón Ribeyro.

Pero Martín Adán no se quedó tan sólo en la superficie de las desconocidas imágenes que delineaban y transformaban el nuevo dibujo urbano. Ya en La casa de cartón, en las últimas líneas, formuló una visión dolida de la ciudad moderna que de algún modo marca el punto de partida de su obra: "La calle ancha nos abre los ojos, violenta, hasta dolernos y cegarnos" (p. 88). Desde la ciudad, Adán emprendía el camino hacia un existencialismo que buscaba, en los espacios del mundo exterior, no el objeto de contemplación sino el ente de reflexión íntima; el espejo que reflejara su mundo interior en el ámbito alienante de la ciudad. En este sentido, La casa de cartón contiene el germen de la poética metafísica que desarrollará en La mano desasida, tal y como plantea Salazar Bondy en el artículo "Noticias de Martín Adán y La mano desasida", cuando escribe que desde su primer libro La casa de cartón - "su palabra poética e irónica zahirió el modo de vida, las convenciones, los ideales y el provincialismo de su clase. Manifestó en aquellas primeras páginas un conflicto vital, una dramática tensión entre su persona social y su persona íntima y espiritual"13.

Al mismo tiempo, en aquellos años primerizos Adán escribió también los poemas de Itinerario de primavera (1927-1932), en los que el estilo vanguardista a la moda aparece a través de imágenes futuristas en poemas de manidos títulos como "Velocidad"

$$
\begin{aligned}
& \text { - Auto, piloto, luz, metal, pájaro, cada } \\
& \text { idea, todo término, jarriba en el cohete } \\
& \text { de una velocidad que ni es humo siquiera!... }{ }^{14}
\end{aligned}
$$

o "Urbanismo":

Extramuros; meaban tufillos de ganado;

el sol, viudo, fregábase la marmita de cobre, y un ficus malarioso, paupérrimo, baldado, ingería la purga de un regato salobre ${ }^{15}$.

Entre estos primeros textos de vanguardia aparecen también los "Poemas Underwood", que Adán incorporó en La casa de cartón. Estos poemas significan una anticipación del prosaísmo en la poesía peruana del siglo XX, y construyen un espacio urbano homogéneo, desnaturalizado, enmascarado por apariencias y ahogado en convenciones:

Prosa dura y magnífica de las calles de la ciudad sin inquietudes estéticas.

Por ellas se va con la policía a la felicidad.

La poesía gafa de las ventanas es un secreto de costureras.

No hay más alegría que la de ser un hombre bien vestido.

\footnotetext{
12 Véase L. Loayza, "Martín Adán en su Casa de cartón", en El Sol de Lima, México, Fondo de Cultura Económica, 1993, p. 128.

${ }^{13}$ S. Salazar Bondy, "Noticias de Martín Adán y La mano desasida", art. cit., p. 19.

${ }^{14}$ M. Adán, en la Antología editada por Mirko Lauer, Madrid, Visor, 1989, p. 24.

${ }^{15}$ Ibidem, p. 25.
} 
Tu corazón es una bocina prohibida por las ordenanzas de tráfico.

Las casas rumian sus paces de buey.

Un mundo plano, rutinario y monótono, de resentimiento y desesperanza:

Si dejaras saber que eres un poeta, irías a la comisaría.

Límpiate de entusiasmos los ojos.

$\ldots$

Los hombres que tropiezas tienen la carne encallecida de oficina.

...

Pasaban obreros con los ojos resentidos con la tarde, con la ciudad $\mathrm{y}$ con los hombres.

En definitiva, un espacio donde la antigua belleza se ha desvanecido para dar paso a la ciudad desencantada que refleja la crisis del mundo moderno:

El mundo está demasiado feo, y no hay manera de embellecerlo.

Sólo puedo imaginarlo como una ciudad de burdeles y fábricas bajo

un aletazo de banderas rojas.

Pero, aparte del contenido social de estos versos, en los "Poemas Underwood" comienza también a entreverse la inclinación hacia una poesía existencialista que culminará en el desgarramiento del yo de La mano desasida, a través de la identificación del poeta con la imagen de la ciudadela incaica. El origen del solipsismo metafísico de Adán hay que buscarlo por tanto en estos primeros textos de vanguardia, cuyas imágenes de la urbe moderna se ven salpicadas por la presencia notable del mundo interior del poeta, que comienza a delinear desde el principio la figura que subyace en toda su obra, la dramática interrogación sobre el yo:

Y amo a los mil hombres que hay en mí, que nacen y mueren a cada instante y no viven nada.

No estoy muy convencido de mi humanidad; no quiero ser como los otros.

No quiero ser feliz con permiso de la policía.

$\ldots$

¿Qué soy, qué quiero? Soy un hombre y no quiero nada.

...

La muerte es sólo un pensamiento, nada más, nada más...

Y yo quiero que sea un largo deleite con su fin, con su calidad.

Este intrincado mundo interior anuncia sus futuras obsesiones, marcadas por la insatisfacción infinita de quien busca incansablemente la perfección, tema central de $L a$ mano desasida:

Yo quiero ser feliz de una manera pequeña. Con dulzura, con esperanza, con insatisfacción, con limitación, con tiempo, con perfección.

$\cdots$

Nada me basta, ni siquiera la muerte; quiero medida, perfección,

Satisfacción, deleite.

¿Cómo he venido a parar en este cinema perdido y humoso? 
La tarde ya se habrá acabado en la ciudad. Y yo todavía me siento la tarde ${ }^{16}$.

La orientación metafísica estaba naciendo en esta primera parte de su producción fusionada con la temática social en el espacio de escritura de la ciudad moderna. Partiendo de estas primeras propuestas literarias, Martín Adán pronto se desvinculó del grupo vanguardista y su singularidad se fue acentuando al tiempo que el peso existencial iba acusando su búsqueda inagotable del yo.

Es en este ámbito en el que se sitúa su gran canto a Machu Picchu, La mano desasida, cuyos primeros fragmentos aparecieron recogidos en 1961, tras diez años de silencio, en una edición preparada por Juan Mejía Baca titulada Nuevas piedras para Machu Picchu; libro conmemorativo del cincuenta aniversario del descubrimiento de la ciudadela incaica que reúne fragmentos de los tres principales cantos a las ruinas: Alturas de Macchu Picchu de Pablo Neruda, Patria completa del peruano Alberto Hidalgo, y los primeros fragmentos de La mano desasida, que hacían su primera aparición en esta edición compartida ${ }^{17}$.

En los siguientes años el poema comenzó su largo proceso de alargamiento. La segunda publicación de La mano desasida es de $1964^{18}$, donde se incluyen nuevos fragmentos que fueron transcritos por el propio editor, Mejía Baca. José Miguel Oviedo recuerda ese proceso desbordante de crecimiento que experimentó La mano desasida en su artículo "Martín Adán ante Machu Picchu": "Se sabía que, presa de un incontenible desborde lírico, Martín Adán alargaba y alargaba su poema, escribiéndolo con caótica vehemencia en libretas, servilletas de papel, envolturas"19, material original que Mejía Baca recopiló y ordenó. Finalmente, la versión completa vio la luz en 1980, con casi trescientas páginas y unos ocho mil versos, en los que un abismo de obsesiones e interrogaciones dan la dimensión del poeta inmerso en el propio ser de la materia, sumido en un diálogo intenso con y entre las piedras en busca de un yo enmascarado desde el comienzo por el pseudónimo y su ironía. Como ha visto Mirko Lauer en su admirable estudio Los exilios interiores. Una introducción a Martín Adán, "la selección de 1964 transmite muy bien la fuerza de un impulso poético; pero el libro entero, aun en su desmesura, revela la exacta dimensión de la experiencia de la que ese impulso proviene" 20 .

El estilo y las formas poéticas utilizadas en este poema debieron adaptarse a la evolución de los temas. Ya en los años treinta Adán comenzó a abandonar el tono vanguardista para crear una poesía que parte de estructuras rítmicas de la tradición castellana (como la décima y el soneto), y sobrecargada de cultismos y arcaísmos léxicos que generan un extrañamiento del idioma; una poesía retórica, gongorina, hermética, en la que Adán se muestra como virtuoso de la forma y la métrica. Sin embargo, en La mano desasida el poeta deja las formas tradicionales para acogerse a una desmesura que se acerca a la escritura automática. Con una nueva tonalidad profética, Adán vuelca su propio ser a través de un torrente de dudas, imprecaciones y contradicciones que se suceden en el

\footnotetext{
${ }^{16}$ M. Adán, "Poemas Underwood", en La casa de cartón, ed. cit., pp. 53-57.

${ }^{17}$ P. Neruda, A. Hidalgo y M. Adán, Nuevas piedras para Machu Picchu, Librería-Editorial Juan Mejía Baca, Lima, 1961.

${ }^{18}$ Lima, Juan Mejía Baca, 1964.

19 J. M. Oviedo, "Martín Adán ante Machu Picchu", en Martín Adán, Obra poética (1928-1971) (con una selección de juicios críticos), ed. cit., p. 263.

${ }^{20}$ M. Lauer, Los exilios interiores. Una introducción a Martín Adán, Lima, Mosca Azul, 1983, pág. 47.
} 
larguísimo diálogo con Machu Picchu. Expresa y alienta sus obsesiones con la naturalidad de un pulso rítmico interior que se tensa, se precipita o se remansa, de acuerdo con la traumática búsqueda del yo poético simbolizado en esa "mano desasida" que busca un asidero en Dios o la poesía.

En esta evolución, la vanguardia había significado un primer aprendizaje efímero pero fundamental como ámbito de despegue de un escritor que había partido de la poetización de su ciudad mutante y de su "yo crepuscular" como símbolo de la misma. Desde la escritura de este espacio público, muy pronto Adán se decidió a tomar un nuevo rumbo, clausurando la temática social para forjar un hermetismo que penetra hacia dentro, y para conducir su poesía hacia esa trascendencia existencial que en La mano desasida se desarrolla como indagación del ser ante el abismo ${ }^{21}$. En suma, partiendo del choque que significa la imagen de la ciudad moderna como lugar de falsas representaciones, Adán transita desde un vanguardismo de contenido social y figuraciones urbanas, hacia el espacio metafísico y filosófico de la ciudad en ruinas.

Frente a una Lima representada como ámbito de alienación y marginación social, la creación poética de Machu Picchu en La mano desasida significa el hallazgo de un espacio primigenio que posibilita, en su autenticidad, en su "trágica desnudez", el encuentro consigo mismo; el hallazgo del yo perdido entre las máscaras de la urbe. El canto está precedido por el poema titulado Escrito a ciegas, en el que el poeta se pregunta: “¿Quién soy? Soy mi qué, /inefable e innumerable",22. Esta búsqueda existencial del yo comienza en el seno de la ciudad, como espacio esencial de la soledad:

$$
\begin{aligned}
& \text { La Soledad es una roca dura } \\
& \text { contra la que arroja el Aire. } \\
& \text { está en cada pared de la Ciudad, } \\
& \text { cómplice, disimulándose... (p. 198) }
\end{aligned}
$$

En Escrito a ciegas la secuencia de preguntas empieza aludiendo a esa imagen de la urbe inmunda que había utilizado como primer referente de su literatura:

$$
\begin{aligned}
& \text { ¿Sabes de la ciudad tanta, } \\
& \text { que no parece ciudad, } \\
& \text { sino cadáver disgregado, } \\
& \text { innumerable e infinitesimal? (p. 200) }
\end{aligned}
$$

En la muchedumbre anónima de la ciudad, desde los "Poemas Underwood", Adán había comenzado a forjar sus obsesiones: la limitación del ser humano, la ineludible presencia de la muerte, y también la búsqueda de perfección que atraviesa toda su obra. El fracaso de la búsqueda existencial en el espacio de la ciudad se resuelve ahora en un nuevo camino que exacerba dicho existencialismo para dar paso al solipsismo metafísico de La mano

\footnotetext{
21 “A mediados de los años 30 - escribe Mirko Lauer-Martín Adán abandonó definitivamente el tono vanguardista y se independizó del proceso poético lineal peruano, de su dinámica de grupos y cambios generacionales. Sus poemas de los años veinte y La casa de cartón son panoramas críticos en que lo social -aunque fuera mediatizado- entra por todas las ventanas. A partir de "La rosa" (1939), los dedicados a Alberto Ureta, las coplas arequipeñas que les siguen y los poemas que van hasta fines de los 40 , los panoramas del mundo exterior se van cerrando, para nunca volver a reabrirse realmente". M. Lauer, "Introducción” a Martín Adán, Antología, ed. cit, p. 8.

${ }^{22}$ Cito por la edición de J. A. Mora, Martín Adán, El más hermoso crepúsculo del mundo (antología), ed. cit., p. 196. En los siguientes versos citados, consigno la página entre paréntesis partiendo de esta edición.
} 
desasida. En contraposición con la imagen inasible y disgregada de la ciudad, en este canto a las ruinas incaicas el poeta intenta un ascenso para protagonizar el encuentro con un espacio indómito que es altura y abismo, y que le permite consumar aquello que la urbe le había negado: la fusión del yo íntimo con Machu Picchu, la identificación con su alma de piedra, de manera que Machu Picchu será a partir de ahora el

$$
\begin{aligned}
& \text { pobre rostro mío, mi alma de piedra, } \\
& \text { exacta y rompidísima, } \\
& \text { innumerable e idéntica. (p. 203) }
\end{aligned}
$$

La ciudadela inca es "innumerable" como la urbe moderna, pero idéntica (al poeta) y exacta (como la palabra). Esta idea de la exactitud (de la búsqueda de la palabra exacta y en definitiva de la suma belleza poética) se reitera con insistencia a lo largo del poema, construyendo ese camino de perfección que el poeta busca en el ascenso a los abismos de las ruinas incaicas: “¿Por dónde se sube al abismo?” (p. 228), se pregunta. La realidad de Machu Picchu se convierte así en la realidad del poeta, que escala esas alturas como quien pretende ascender a la perfección, en su caso, de la poesía:

¿Qué palabra simple y precisa inventaré para hablarte, Mi Piedra? (p. 203)

Ante la ciudad milenaria - espejo del poeta- la revelación última del yo poético posee la dimensión trágica de una pequeñez desnuda, hecha de verso como realidad única del escritor:

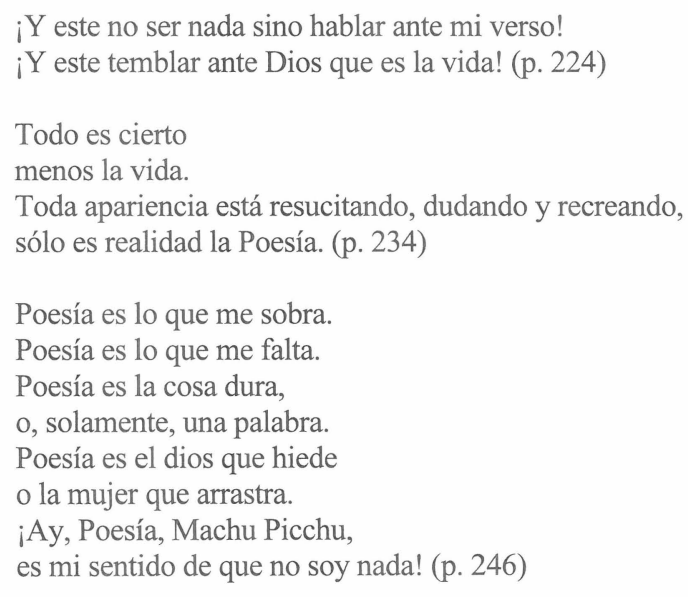

Pero al mismo tiempo, Adán será también el poeta demiurgo que hunde la mano en la raíz de sí mismo para identificarse con Machu Picchu como imagen de un dios humanizado que creó el mundo a través de la palabra:

$¡$ Este sentirse uno Dios ante la propia conciencia y ante la propia herejía...

¡Este haberte hecho un humano como yo (...)

¡Este tu estar a mi medida humana,

sin suelo, sin habitantes y con sola tu agonía! (p. 224) 


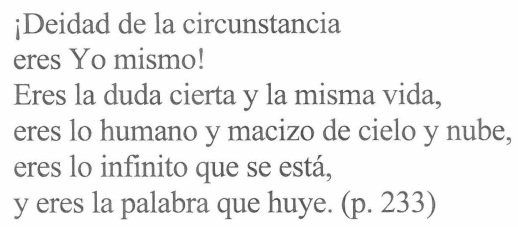

Figuración del lugar sin tiempo, sin habitantes, sin suelo, Machu Picchu es el reverso de la ciudad moderna; el espacio que simboliza ese otro lado indecible desde el que Martín Adán se interroga sobre la vida, la muerte, dios o la poesía. Es, en definitiva, el "esqueleto de la maravilla", o el espejo enajenado que permitió al poeta volcar en el verso su autobiografía intelectual. En La mano desasida esta imagen subjetivada de Machu Picchu apunta hacia la desviación del interés del escritor que, habiendo partido de un mundo exterior del que se autoexcluye y que le margina -representado por la Lima moderna-, experimenta un repliegue radical hacia la interioridad del hombre que ya sólo puede examinar dentro de sí mismo, y que encuentra en la ciudad ancestral de los Incas a su interlocutor ideal. Este movimiento hacia la búsqueda inagotable del ser en la obra de Martín Adán había germinado ya en sus primeros escritos, y se resuelve en esas dos imágenes urbanas contrapuestas que condensan los extremos de la evolución de su obra: de la vanguardia poética que dibujó las primeras imágenes de "Lima, la horrible", a la metafísica solipsista que le permitió ascender, sin saber el camino, hasta la ciudad del abismo, de la soledad, y de la poesía.

\section{REFERENCIAS BIBLIOGRÁFICAS}

ADÁN, M., La casa de cartón, Lima, Mejía Baca, 1974.

ADÁN, M., La mano desasida, Lima, Juan Mejía Baca, 1964.

ADÁN, M., Obra poética, Lima, Edubanco, 1980.

ADÁN, M., Antología, Mirko Lauer (ed.), Madrid, Visor, 1989.

ADÁN, M., Los exilios interiores. Una introducción a Martín Adán, Lima, Mosca Azul, 1983.

LOAYZA, L., "Martín Adán en su Casa de cartón”, en El Sol de Lima, México, Fondo de Cultura Económica, 1993.

MARIÁTEGUI, J. C., Siete ensayos de interpretación de la realidad peruana (1928), México, Era, 1979.

MORA, J. A., Martín Adán. El más hermoso crepúsculo del mundo (antología), México, Fondo de Cultura Económica, 1992.

PABLO NERUDA, Alberto HIDALGO y Martín ADÁN, Nuevas piedras para Machu Picchu, Librería-Editorial Juan Mejía Baca, Lima, 1961.

OVIEDO, J. M., "Martín Adán ante Machu Picchu”, en Martín Adán, Obra poética (19281971) (con una selección de juicios críticos), Lima, Instituto Nacional de Cultura, 1971, pp. 263-266. 
SALAZAR BONDY, S., "El conflicto vital de Martín Adán”, en Martín Adán, Obra poética (1928-1971) (con una selección de juicios críticos), Lima, Instituto Nacional de Cultura, 1971 (pp. 257-262).

SALAZAR BONDY, S., "Noticias de Martín Adán y La mano desasida", Revista de la Universidad de México, n 1, vol. XVI (septiembre 1961), México.

SÁNCHEZ, L. A., Panorama de la literatura del Perú, Lima, Milla Batres, 1974. 
